This item was submitted to Loughborough's Research Repository by the author.

Items in Figshare are protected by copyright, with all rights reserved, unless otherwise indicated.

\title{
A parametric study of automotive rear end geometries on rear soiling
}

PLEASE CITE THE PUBLISHED VERSION

http://dx.doi.org/10.4271/2017-01-1511

\section{PUBLISHER}

(C) SAE International

\section{VERSION}

NA (Not Applicable or Unknown)

\section{PUBLISHER STATEMENT}

This work is made available according to the conditions of the Creative Commons Attribution-NonCommercialNoDerivatives 4.0 International (CC BY-NC-ND 4.0) licence. Full details of this licence are available at: https://creativecommons.org/licenses/by-nc-nd/4.0/

\section{LICENCE}

CC BY-NC-ND 4.0

\section{REPOSITORY RECORD}

Kabanovs, Anton, Graham Hodgson, Andrew Garmory, Martin A. Passmore, and Adrian P. Gaylard. 2017. "A Parametric Study of Automotive Rear End Geometries on Rear Soiling". figshare.

https://hdl.handle.net/2134/24495. 


\title{
A Parametric Study of Automotive Rear End Geometries on Rear Soiling
}

\author{
Anton Kabanovs, Graham Hodgson, Andrew Garmory, and Martin Passmore \\ Loughborough University \\ Adrian Gaylard \\ Jaguar Land Rover
}

\begin{abstract}
The motivation for this paper is to consider the effect of rear end geometry on rear soiling using a representative generic SUV body. In particular the effect of varying the top slant angle is considered using both experiment and Computational Fluid Dynamics (CFD). Previous work has shown that slant angle has a significant effect on wake shape and drag and the work here extends this to investigate the effect on rear soiling. It is hoped that this work can provide an insight into the likely effect of such geometry changes on the soiling of similarly shaped road vehicles. To increase the generality of results, and to allow comparison with previously obtained aerodynamic data, a 25\% scale generic SUV model is used in the Loughborough University Large Wind Tunnel. UV doped water is sprayed from a position located at the bottom of the left rear tyre to simulate the creation of spray from this tyre. Having a single source of contamination simplifies the configuration of both experimental tests and simulations. It also improves analysis by allowing the soiling pattern from only one wheel to be seen in isolation. In order to provide further insight into the flowfield and its interaction with the spray CFD simulations are also performed at the same scale. A Detached Eddy Simulation approach is used, specifically the Spalart Allmaras formulation of the IDDES CFD model. Lagrangian particle tracking is used to model the dispersed phase. This CFD methodology has been found to give good agreement for soiling pattern with experiment for baseline cases.
\end{abstract}

CITATION: Kabanovs, A., Hodgson, G., Garmory, A., Passmore, M. et al., "A Parametric Study of Automotive Rear End Geometries on Rear Soiling," SAE Int. J. Passeng. Cars - Mech. Syst. 10(2):2017, doi:10.4271/2017-01-1511.

\section{INTRODUCTION}

The management of surface contamination, or soiling, of vehicles is important to all vehicle manufacturers. Three sources of contamination are generally described [1]. Primary sources are contamination directly resulting from rain; third-party contamination refers to contaminants resulting from other vehicles and self-soiling refers to contaminants resulting from spray generated by the vehicle itself. The work reported here is focused on the latter phenomenon that is particularly relevant for vehicles with blunt rear geometries, such as off-road vehicles, Sports Utility Vehicles (SUVs) and estates (Station wagons) [2]. Self soiling is particularly important for these vehicles because the blunt rear geometry causes the formation of strong large-scale recirculating vortices that draw the spray towards the base [ $\underline{3}$ ]. As a result, base contamination generates various issues for the driver and passengers including reduced visibility (for both the driver and any camera systems), a reduction in perceived quality and the potential for soiling to be transported to skin and clothing.

As the rear soiling is closely linked to the structure of the wake the issue of rear surface contamination is best addressed concurrently with aerodynamic drag. For example, for commercial vehicles a reduction in overall vehicle drag can also lead to a reduction in spray $[\underline{4}, \underline{5}]$. Therefore, the ability to predict the self-soiling phenomenon early in a vehicle development programme would provide a useful insight and allow designers and aerodynamicists the opportunity to resolve soiling issues alongside the more usual areas of concern such as drag reduction, aero-acoustics and cross-wind stability.

Much of the published work has understandably focused on specific vehicles. For example, a very comprehensive study into the prediction of surface contamination for a detailed SUV has been reported by Gaylard and Duncan [3] ], as well as Gaylard et al. [무 $\underline{7}]$. Conversely, simplified bodies that lack details and styling of specific vehicles, are commonly used to study automotive aerodynamics. These bodies allow the investigation of the relevant flow features in well characterised and repeatable environments with geometries that can be employed by different research groups. The work reported here applies this same practice by considering surface contamination in controlled wind-tunnel conditions with a simplified vehicle body (Generic SUV) and conducting the same experiments numerically. This will improve the generality of any conclusions.

Whereas much published work $[\underline{7}, \underline{8}, \underline{9}, \underline{10}]$ has focused on the final outcome with regard to the surface contamination, or on comparing CFD simulations with experimental work, the work presented here studies the variation of base contamination with changing roof slant angle. Roof slant angle variations were selected for the study because 
they are commonly employed as a drag reduction method [11]. The work reported contains a thorough description of the experimental and numerical methods and analysis of the results.

\section{EXPERIMENTAL METHODOLOGY}

\section{Facilities}

Testing was performed in the Loughborough University Wind Tunnel, Figure 1, full details of which can be found in [12]. The operating velocity in the test section was $40 \mathrm{~m} \cdot \mathrm{s}^{-1}$. The freestream turbulence intensity in the middle of an empty test section is approximately 0.2 $\%$ and flow uniformity $\pm 0.4 \%$. The pressure data presented in this work has been corrected to account for blockage effects using a continuity based correction method shown in Equation (1) [13].

$$
C_{P-\text { corrected }}=\frac{C_{P}+2 \frac{M A}{T A}}{1+2 \frac{M A}{T A}}
$$

In addition, force coefficients have been calculated using the corrected value for velocity, estimated using a continuity correction seen in Equation (2) [14]. In the equations, TA and MA correspond to the wind tunnel cross section area and the model frontal area, respectively. $\mathrm{C}_{\mathrm{p}}$ and $\mathrm{C}_{\mathrm{p} \text {-corrected }}$ are the recorded surface pressure coefficient and the corrected surface pressure coefficient, respectively. Finally, $v$ and $v_{\text {corrected }}$ are the recorded reference velocity and the corrected reference velocity respectively. These pressure and force correction procedures have been also applied to CFD data.

$$
v_{\text {corrected }}=\frac{v \cdot T A}{T A-M A}
$$

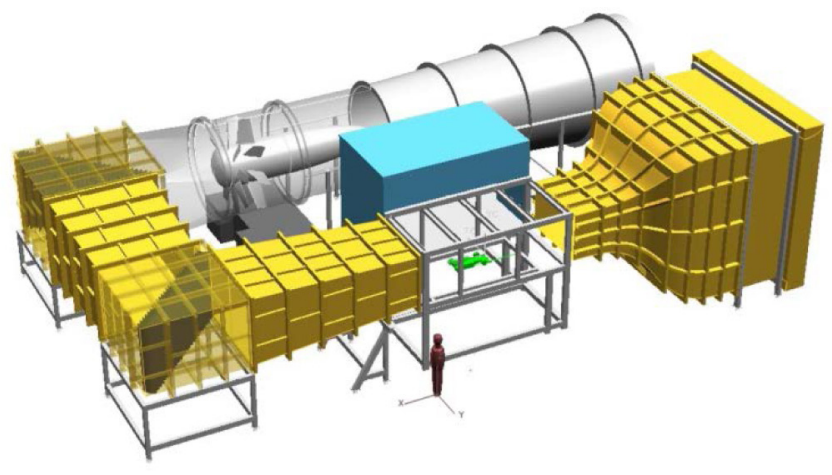

Figure 1. The Loughborough University Wind Tunnel

\section{Model}

A quarter scale generic SUV Model, Figure 2, was used for this work. The model is constructed of a machinable model board and gives a blockage ratio of $5 \%$ in the $2.5 \mathrm{~m}^{2}$ working section. The model has large leading edge radii to prevent separation and sharp edges at the rear. The geometry is representative of a typical SUV with configurable elements including ride heights, roof tapers, diffusers and roughness strips. More information can be found in [15]. For this study the diffuser is fixed at 10 degrees, no roughness strips are present and three taper angles are investigated; 0, 10 and 20 degrees. The ride height is fixed at $65 \mathrm{~mm}$. SUVs have large bases and these are prone to contamination effects. As such, this model is highly suited to such a parametric study.
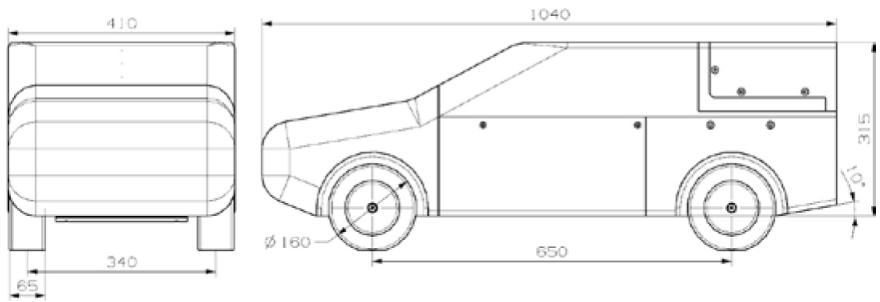

Figure 2. Dimensions (in $\mathrm{mm}$ ) of the generic SUV model

Figure 3 shows the side profile of the model with the three tested roof tapers colour coded: grey 0 degree, blue 10 degree and pink 20 degree. The 10 degree diffuser is also shown in blue.

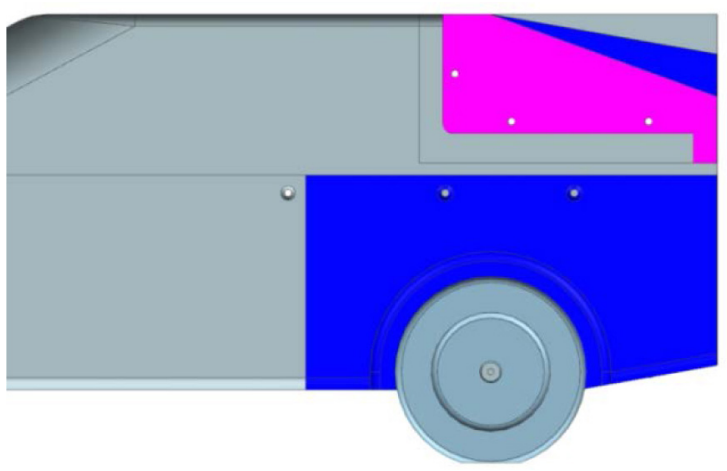

Figure 3. Roof taper geometries

\section{Droplet Characterisation}

To ensure simulations were matched to experiments the droplet characteristics have been measured in a separate Phase Doppler Anemometry (PDA) experiment. This allows the simulation to more accurately replicate the experiment than in previous work [9].

The PDA setup can be seen in Figure 4 with equipment as described in $[16,17]$. Traverses at 2, 3, 7, 10, 20 and $30 \mathrm{~mm}$ from the nozzle outlet face were conducted on the half-cone in a no-flow (air) arrangement. These tests identified droplet diameter (with a resolution of approximately 0.18 microns) and two velocity components for every droplet over a $5 \mathrm{~s}$ test at points typically $1-2$ mm separation.
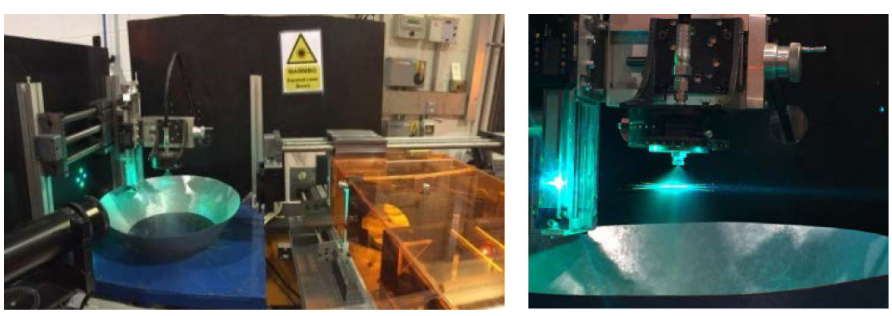

Figure 4. PDA experimental setup 


\section{Seeding Setup}

A schematic of the seeding setup used in the wind tunnel can be seen in Figure 5. A single nozzle, installed $86 \mathrm{~mm}$ behind the rear near-side wheel center and directed 45 degrees downstream was used. This location was chosen to reasonably represent the typical source [7] of self-soiling and ensure that sufficient particles of fluid were entrained in the body and wheel wakes. Using a single source, rather than one located behind each rear wheel ensures that a clear analysis of the source and outcome can be achieved. A pair of solenoid valves controlled electronically allow for known, fixed duration of spray injection ensuring repeatable spray characteristics that can be provided as input to a numerical model. This setup also ensured a sharp start and end to injection, reducing experimental variation.

A mixture of de-ionised water and UV dye (Uvitex at $0.03 \%$ concentration) was used as the contaminant with an UV lamp as the illumination source. Following every test the light source and a DSLR camera were placed in the tunnel and an image captured. A testing pressure of 110 bar resulted in a mass flow rate of approximately $3.5 \mathrm{~g} . \mathrm{s}^{-1}$.

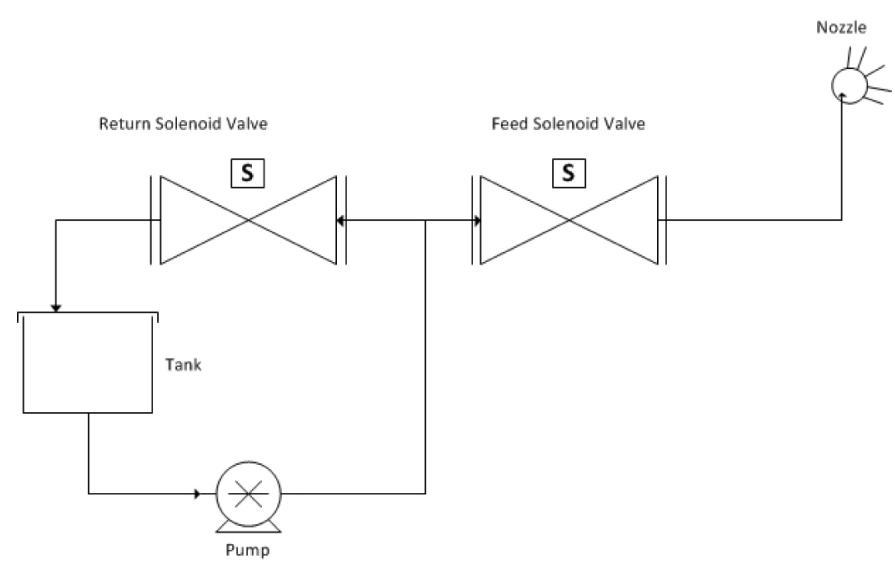

Figure 5. Seeding setup

\section{Measurements}

The model was run in the wind tunnel for sufficient time $(\sim 30 \mathrm{~s})$ to settle prior to the spraying and every injection was $12 \mathrm{~s}$ in duration. This time was selected to be short enough to ensure no rivulet formation occurred in any configuration and long enough to account for any very low frequency wake structures that may impact soiling. Rivulet formation, while of interest in the broader Exterior Water Management (EWM) field, ensures the location of the droplet impact is lost and relocates the mass of fluid to the lower regions of the base. Captured images are stored in RAW format to ensure image processing is consistent across tests. Combined with an appropriate calibration the Beer-Lambert Law (Equation 3) can be used to calculate a depth of fluid from an image intensity.

$$
g_{t}=\left[A\left(1-e^{B x}\right)+C\right]^{D}
$$

The calibration is achieved by placing a calibration vessel similar to that used in $[\underline{9}, \underline{18}]$ in the tunnel next to the model at the end of every test so that it is captured in the image. Figure 6 shows the variation of intensity with depth across the calibration vessel. It can be seen that with the illumination, exposure and dye concentration used that the relationship is reasonably linear, i.e. intensity is directly proportional to depth.

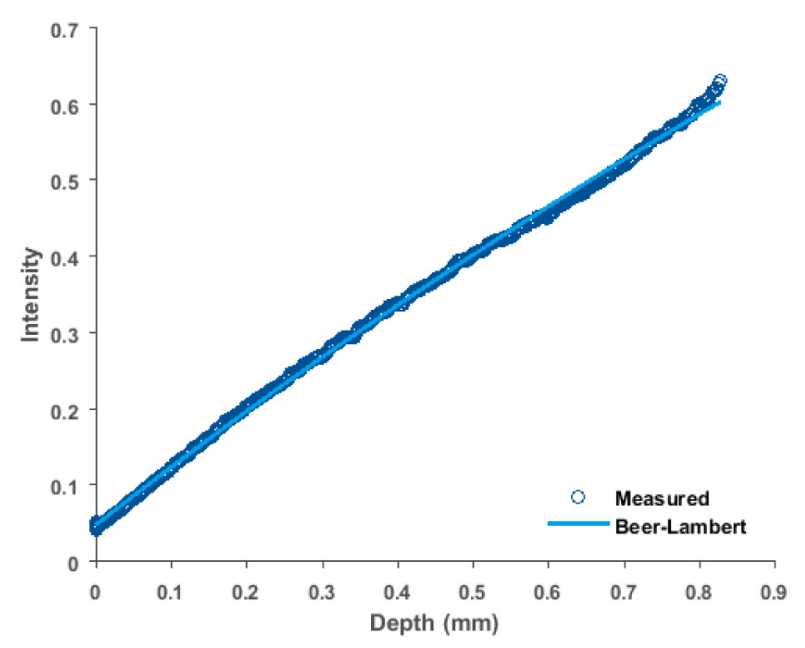

Figure 6. Typical Beer-Lambert curve fit

\section{CFD CONFIGURATION}

\section{Mathematical Models}

Computational simulations were performed using OpenFOAM $\AA$, an open source CFD tool. The continuous phase (air) was computed using the Improved Delayed DES (IDDES) formulation of the Spalart-Allmaras Detached Eddy Model. The DES formulation [19] and its recent modification, delayed DES (DDES) [20], use RANS to compute the whole or at least the major part of the attached boundary layer, while an LES approach is used in regions with separated flow. The recent modification of the DDES model, Improved DDES (IDDES), has an enhanced capability to identify which mode (RANS or LES) it should be operating in near the wall [21]. In addition, it allows some of the boundary layer to be resolved by LES, resulting in a quicker transition to resolved turbulence and hence increased resolved turbulence activity near the wall [리].

In this study the Navier-Stokes equations were solved using the PISO (Pressure Implicit with Splitting of Operators) algorithm. The maximum global Courant Friedrichs Lewy (CFL) number, defined as

$$
C F L=\frac{U * \Delta t}{\Delta x}
$$

was found to be of order 10, however the CFL number in the separated region was less than 1 to ensure that eddies are resolved in time and space. The dispersed phase (water particles) was computed using the Lagrangian approach [22]. The Lagrangian particle tracking approach allows simulations to be simplified by tracking groups of particles together as a numerical parcel. Although increasing the number of parcel streams (in the limit to match the number of 
particles) improves accuracy by creating a larger ensemble of tracks, this also increases computational cost. For this reason, in this work a total of 17.5 million parcels were released, each representing a number of particles of a given size. The total liquid mass was equally split between parcels.

The Lagrangian particle tracking was carried out concurrently with the PISO algorithm, meaning that the dynamics of particles were calculated within the solver at each time step, enabling particles to respond to the unsteady turbulent flow. In this study particles were subjected to drag (Schiller-Naumann correlation, shown in Equation (7) [23]), gravity and shear lift (Saffman Mei lift [24]) forces, as shown in Equation (5).

$$
\begin{aligned}
F=-\frac{\pi D^{2}}{8} \rho C_{d} \mid u_{p} & -u \mid\left(u_{p}-u\right) \\
& +1.61 \mu_{c} D\left|u_{p}-u\right| \sqrt{R e_{G}}+m_{p} g
\end{aligned}
$$

Where

$$
\operatorname{Re}_{G}=\frac{D^{2}}{v_{c}} \frac{d u}{d y}
$$

And

$$
\begin{gathered}
C_{d}= \begin{cases}\frac{24\left(1+0.15 R e^{0.687}\right)}{R e} & R e \leq 1000 \\
0.44 & R e>1000\end{cases} \\
R e=\frac{\rho\left|u_{p}-u\right| D}{\mu}
\end{gathered}
$$

A stochastic dispersion model (Gosman and Ioannides [25]) was used to model the influence of the unresolved turbulent content on the motion of particles. However the sub-grid turbulence in the wake was found to be small, typically less than $90 \%$. Considering that a high mass loading is found in the injection area, the two-way momentum coupling (particle-fluid interaction) was taken into account through a semi-implicit scheme. Particle-particle interaction was ignored in this study.

\section{Computational Domain and Boundary Conditions}

The computational grids were generated using snappyHexMesh, a meshing algorithm available within the OpenFOAM $®$ software suit. The meshes generated by this utility contain hexahedra and splithexahedra cells. The OpenFOAM particle tracking makes use of a tetrahedral decomposition of the mesh and the use of snappyHexMesh ensures that meshes are fully compatible with this feature.
Figure 7 and Figure 8 present the general approach to generating meshes in this study. The whole domain can be split into three volumes as shown in Figure 7. The middle volume represents the test section, in which walls are subjected to no-slip boundary condition. The boundary layer starts developing approximately $4.7 \mathrm{~m}$ ahead of the model. This length is based on the distance required for the boundary layer to reach the thickness previously identified in the tunnel. In addition, the middle volume has divergent walls, matching those in the wind tunnel, to make sure that the pressure gradient is zero when the model is not present. Table 1 provides information on dimensions of the domain, as well as the location of the model relative to the inlet and the outlet of the control volume.

Table 1. Dimensions of the computational domain

\begin{tabular}{|l|l|}
\hline Length & $28.0 \mathrm{~m}$ \\
\hline Height & $1.32 \mathrm{~m}$ \\
\hline Width before wall divergence & $1.92 \mathrm{~m}$ \\
\hline Width after wall divergence & $1.9704 \mathrm{~m}$ \\
\hline Divergence angle & $0.16 \mathrm{deg}$ \\
\hline Distance to inlet from the model base & $13.36 \mathrm{~m}$ \\
\hline Distance to outlet from the model base & $14.64 \mathrm{~m}$ \\
\hline
\end{tabular}

Inlet velocity was $40 \mathrm{~m} / \mathrm{s}$, matching the one used in aerodynamics tests and soiling experiments. This corresponds to a length-based Reynolds number of 2.77 million.

Refinement regions and prism layers were added around the model and in the rear portion of the car as shown in Figure 8 to capture strong gradients in the flow (including separated flow regions). A high $\mathrm{y}+$ approach with suitable wall functions was used at the walls to reduce the mesh size to some degree. Each mesh used in the study contains approximately 67 million cells, with the smallest cell equal to $0.001 \mathrm{~m}$. A very similar computational procedure was used in [26] in which a good agreement with an experiment was obtained in the same wind tunnel arrangement.

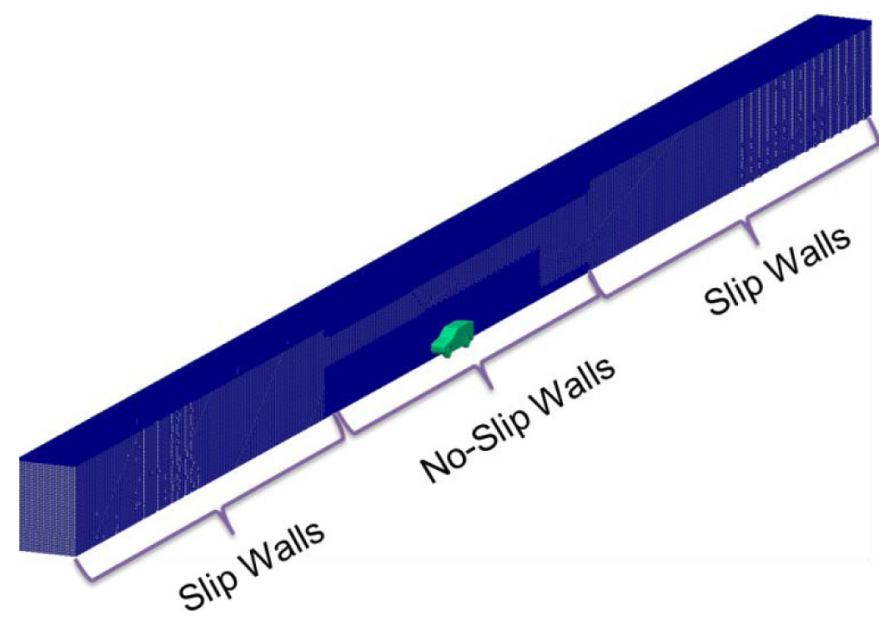

Figure 7. Computational domain 


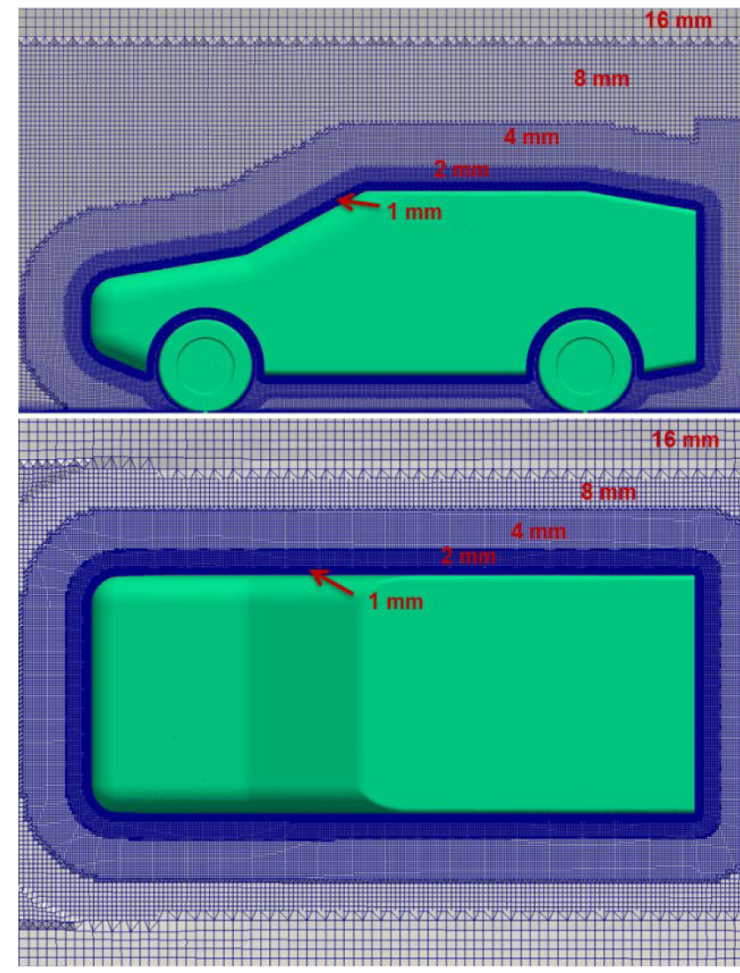

Figure 8. Mesh generation

\section{Spray Model}

The data collected with the PDA system was used to intialise the spray model. Figure 9 shows the population of spherical droplets at each traverse captured by PDA. In CFD simulations the droplet size distribution measured at $10 \mathrm{~mm}$ away from the nozzle (see Figure 10) was used because the spray results show that the droplets' distribution is fully developed at this distance, i.e. all droplet breakup and coalescence is finished. The total cone angle was identified to be 90 degrees, allowing approximately $98 \%$ of the measured data at the aforementioned axial position to be used, as shown in Figure 9. The data measured at traverse points outside the cone angle were ignored.

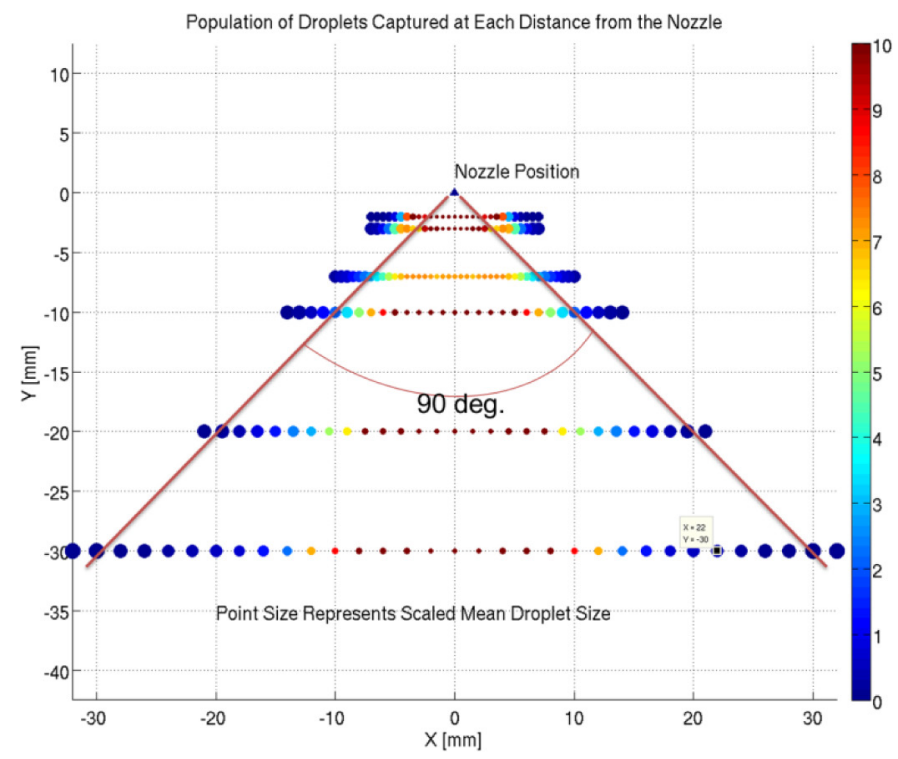

Figure 9. Droplet population at each traverse
It can be seen from Figure 10 that the droplet size distribution at the center of the cone is significantly different from that at the edge of the cone. To account for this in the CFD, ten hollow cone injectors were used, assembled one inside another as seen in Figure 11, and positioned in the same location as in the experiments. In the figure, each colour corresponds to a new injector. Each injector was setup to generate a specific particle size profile as seen in Figure 10.

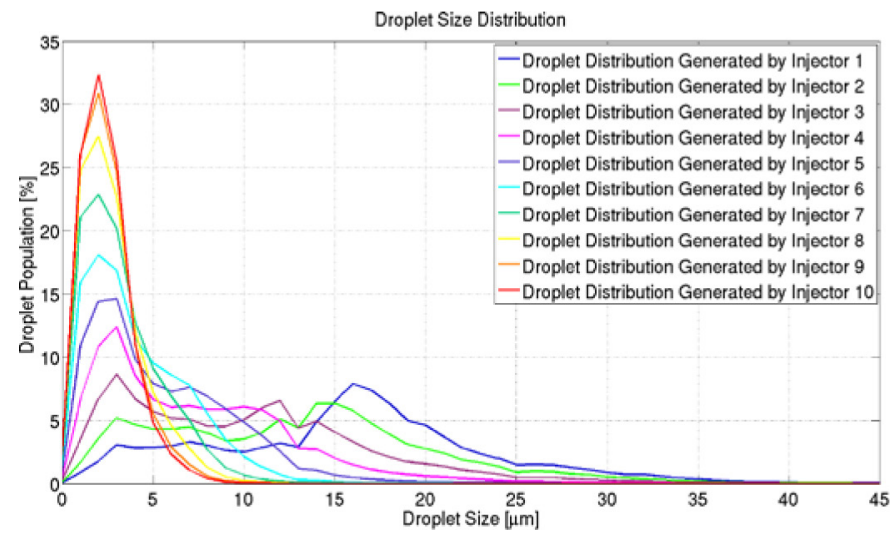

Figure 10. Droplet size distribution at different traverse points at the axial position of $10 \mathrm{~mm}$
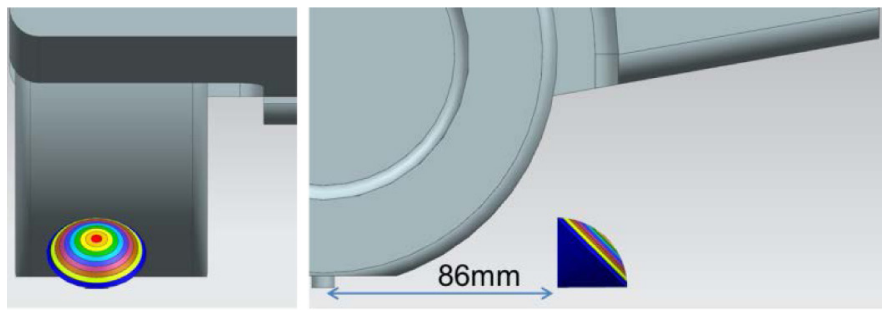

Figure 11. Injection approach

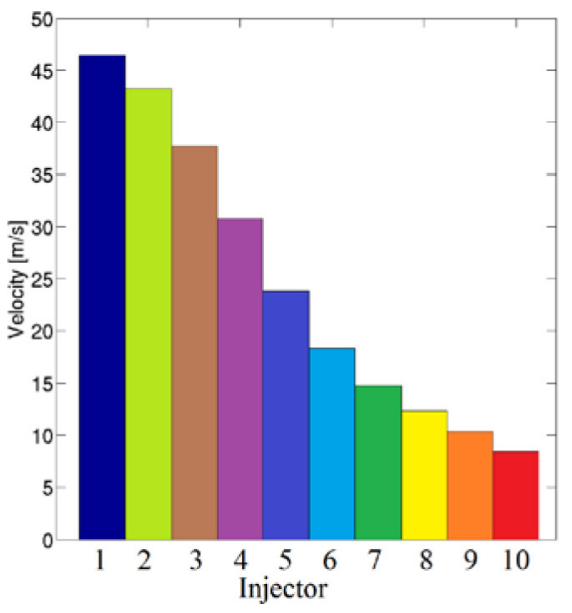

Figure 12. Initial velocity profile

The PDA data for the droplets was acquired in a Stokes flow, in which the high initial momentum decays rapidly due to viscous forces. However, in the wind tunnel experiments the flow is far from stationary; so it was important to estimate an accurate initial momentum of the spray to be able to accurately model spray in the diffuser area. This was achieved by using the average speed of droplets measured $3 \mathrm{~mm}$ away from the nozzle as the initial speed of computational particles leaving the injectors; again with different 
velocities for each injector. Figure 12 shows the injection velocity profile used in the simulations with colours matching those in Figure $\underline{10}$ and Figure 11. Figure 13 compares the simulated spray and the spray observed in experiments. It is evident that there is a good qualitative match in terms of the cone angle and spray momentum, with spray in both cases impacting the diffuser.
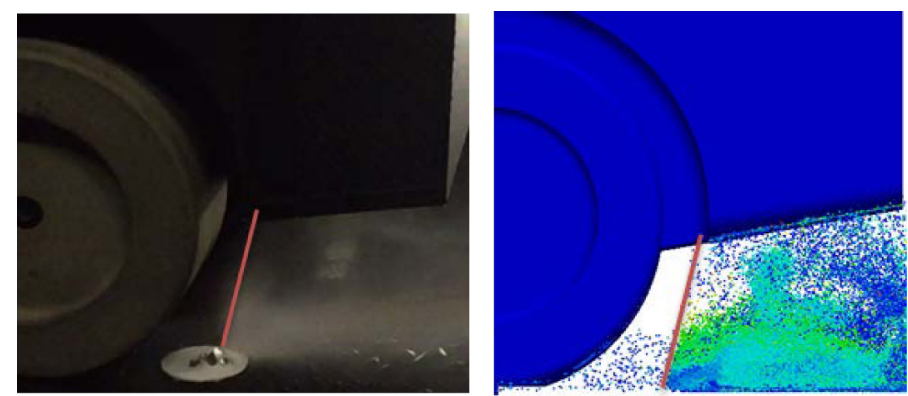

Figure 13. Experimental spray vs. simulated spray

In the multi-phase simulation, the spray was injected for the duration of 1 second. An extra one fifth of a second was given for the remaining spray particles to either escape the wake volume or accumulate on the base surface.

\section{RESULTS}

\section{Aerodynamic Results}

For each SUV configuration an initial aerodynamic (single-phase) simulation was run to establish the flow field. One second was found to be enough for the flow to settle down, after which the injection of particles, as well as the averaging of aerodynamic forces, was initiated. Table 2 shows drag and lift data for all three cases obtained in experiments and CFD. Figure 14 presents the time averaged pressure distribution on the base of the SUV model for the three configurations. It should be emphasised that the experimental single-phase data had been collected as part of a separate study [27].

Table 2. Comparison of force coefficients

\begin{tabular}{|c|c|c|c|c|c|c|}
\hline \multirow{2}{*}{} & \multicolumn{2}{|c|}{ Roof Taper 20 } & \multicolumn{2}{c|}{ Roof Taper 10 } & \multicolumn{2}{c|}{ Roof Taper 0 } \\
\cline { 2 - 7 } & EXP & CFD & EXP & CFD & EXP & CFD \\
\hline Cd & 0.394 & 0.391 & 0.383 & 0.373 & 0.434 & 0.423 \\
\hline Cl & 0.477 & 0.3106 & 0.312 & 0.150 & 0.127 & -0.019 \\
\hline
\end{tabular}

CFD results obtained for SUV configurations with 10 and 0 degree roof tapers match well with the experimental results in terms of base pressure distribution, suggesting that the wake structure is also captured. However, CFD predicts weaker suction in the model base area, leading to a slight mismatch in the base pressure values. This is consistent with the CFD prediction of drag, which is higher in the experiments. Nevertheless, the error in the prediction of drag is small and is below $3 \%$ for all three configurations.

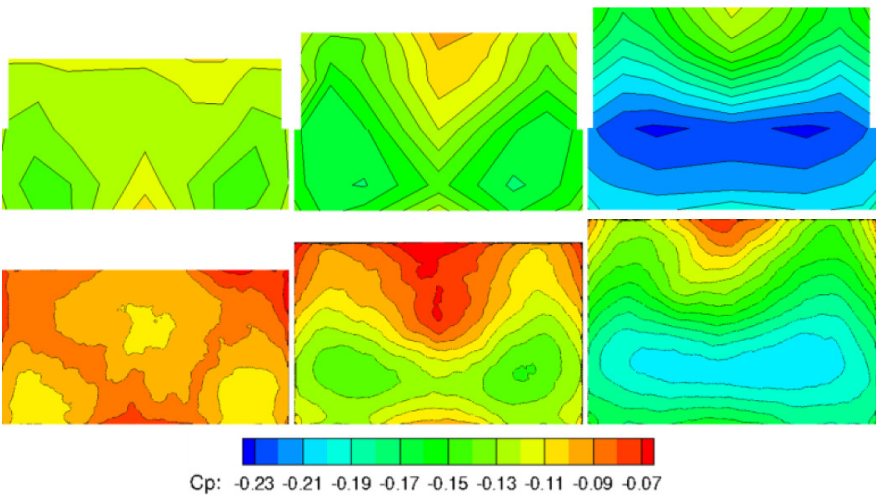

Figure 14. Base pressures; Experimental top, numerical bottom. Decreasing taper left to right.

Computational results obtained for the SUV configuration with the 20 degree roof taper, although considered satisfactory for this study, do not match experimental results as well as for the other configurations. Low pressure regions, consistent with vortices, are seen in the lower corners but the magnitude of the pressure is too high. This suggests the presence of flow features is correctly predicted if not the exact details. The mismatch may be due to an inaccurate prediction of flow separation from the roof taper. This may be attributed to the use of near-wall models to predict the development of boundary layer around the model (i.e. the first cell was in the log-law region). To improve the accuracy, the first few cells at the wall could be reduced so that the first cell is within the viscous sublayer. However it should be noted that predicting the precise location of flow separation is challenging for any turbulence modelling approach.

It can be seen that CFD under-predicts lift for all three configurations. This has been also reported in [26], who studied a different configuration of the very same model and suggested that one of the possible reasons is the failure to accurately model interaction of the boundary layer with the underbody of the model. This is because the ground clearance is small and hence the boundary layer may have a significant influence on the underbody pressure, thus affecting lift. Overall the agreement between CFD and experiemental aerodynamic data is considered strong enough to use the CFD flow field to aid understanding of the experimental soiling results.

\section{Soiling Results}

Figure 15 shows base contamination for three SUV configurations obtained experimentally and numerically. In the figure base surfaces are coloured by local soiling intensity. This allows for qualitative comparison of the most contaminated rear-surface areas between three configurations. Additionally, typical comparisons between experimental and numeric results can be made.

The experimental results show greater dispersion of contaminant on the base. There may be some noise due to the near linear BeerLambert curve fit, but the dispersion is a manifestation of the stochastic nature of base soiling, especially given the duration of the tests. Further, it would be reasonable to assume that experimental results would show more dispersed particles across the base than 
CFD due to the numerical approach that uses parcels that contain a number of individual particles, rather than the particles themselves. Even so, the patterns of contamination are sufficiently visible.

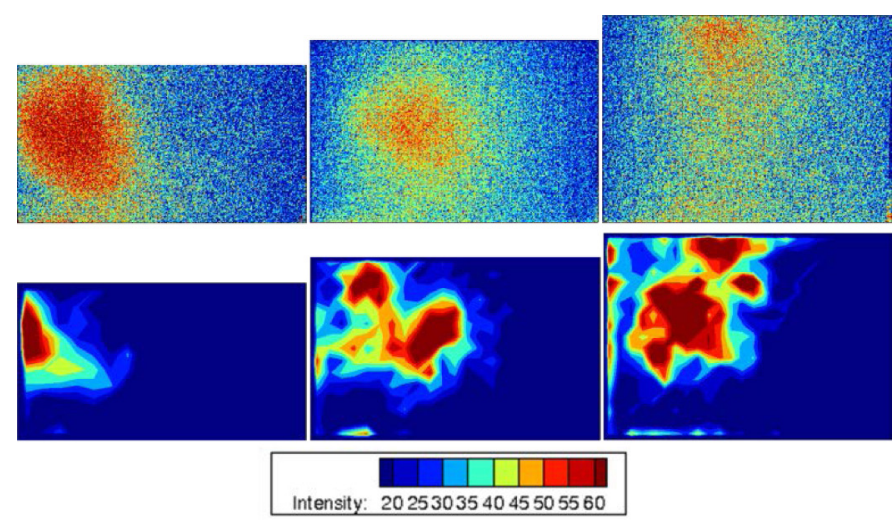

Figure 15. Soiling Intensities; Experimental top, numerical bottom. Decreasing taper left-to-right.

As can be seen in Figure 15 the numeric results are matched well to the experimental ones. Both the location and dispersion trends are apparent. The apparent lower resolution in the CFD results are due to integrating the contamination on the base using a coarsened grid. As the Lagrangian approach tracks parcels rather than individual particles and every parcel can contain large numbers of particles; all of which would have a different trajectory from that of the parcel. Therefore, integrating deposition over larger areas is used to counterbalance the reduced refinement of spray and hence get more uniform patterns of contamination.

It can be seen that as the taper angle increases the soiling becomes confined to a smaller region. Or conversely as taper angle is reduced the contamination has more dispersion in the larger wake. This results in greater distribution across the base.

At the 20 degree taper the soiling is focused on the mid-upper side on the same side as the spray source, whereas with decreasing taper angle the soiling is more diffuse and central. These effects are consistent with the smaller wake observed in the CFD results with the 20 degree taper angle, as seen in Figure 16 and Figure 17. The high downwash generated by the 20 degree roof taper pushes the core of the wake closer to the ground where the spray is injected. As a result, droplets have less time to disperse as they are drawn earlier into the wake. In addition, the separation at the centre near the trailing edge of the taper creates a horseshoe shaped wake, seen in Figure 16 and Figure 18. This has the effect of pushing the contamination to the side of the base. Figure 18 also shows a strong recirculating vortex generated by the interaction between flow on the slant and from the sides (the rear pillar), which also influences base contamination. It is believed that this is a source of difference between CFD and experiments. It can be observed in Figure 15 that CFD predicts a high intensity peak located closer to the edge of the base than that in the experiment. The reason for this may be due to an innaccurate prediction of the rear pillar vortex.

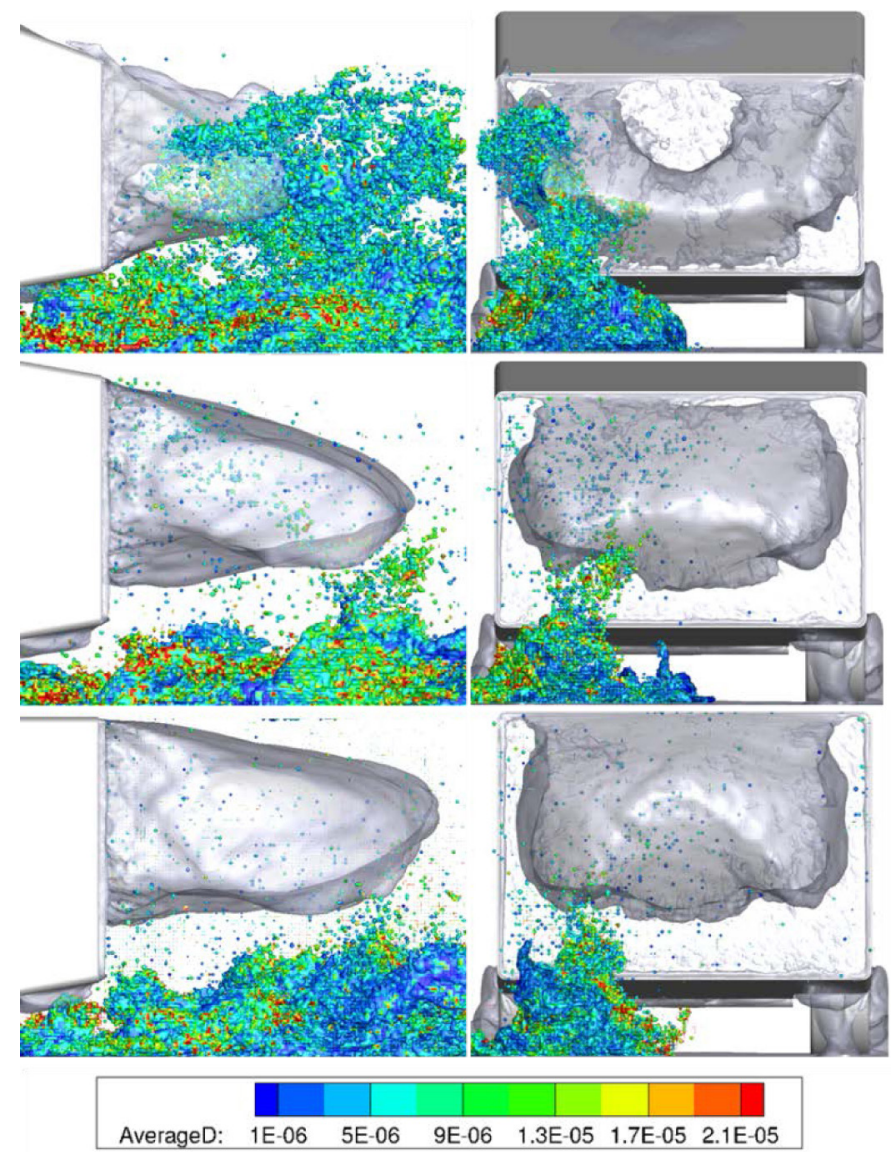

Figure 16. Droplet dispersion in the wake. Droplets represented by an isosurface coloured by average size with zero velocity isosurface (time averaged) in grey. Zero roof taper top, ten middle and twenty bottom.

For the 10 degree taper the contamination area is more central and diffuse. This can be explained by studying Figure 17, which shows the presence of a recirculating vortex at the top of the base. The droplets, however, are carried by the bottom vortex that spans up to about the middle of the base. It can be also seen in Figure 16 that the spray is being brought into the wake near the end of the wake. Due to the longer wake size there is a more time for the particles to disperse in the flow compared to the 20 degree taper. Figure 18 also shows the presence of a rear pillar vortex, however it is not as strong as in the case of 20 degree taper. It is likely that the pillar vortex again has an effect on base contamination, though not as strong, as shown by the reduced biasing of the contamination to the side of the base. In addition to the high contamination near the middle of the base, it also predicts strong particle impingement in the area close to the left top corner of the base.

For the 0 degree taper the contamination is more central again and closer to the roof. Figure 17 indicates that there is minimal downwash, with the bottom vortex spanning across the whole height of the base. The upwash from the diffuser is still evident, pushing the spray towards the top of the base. The roof taper angle of 0 degrees also results in a longer wake than has been observed in previous cases. Since the majority of spray does not have enough momentum 
to penetrate the shear layer of the wake, and enter from the end of the wake, particles are carried further away from the base and hence disperse more.

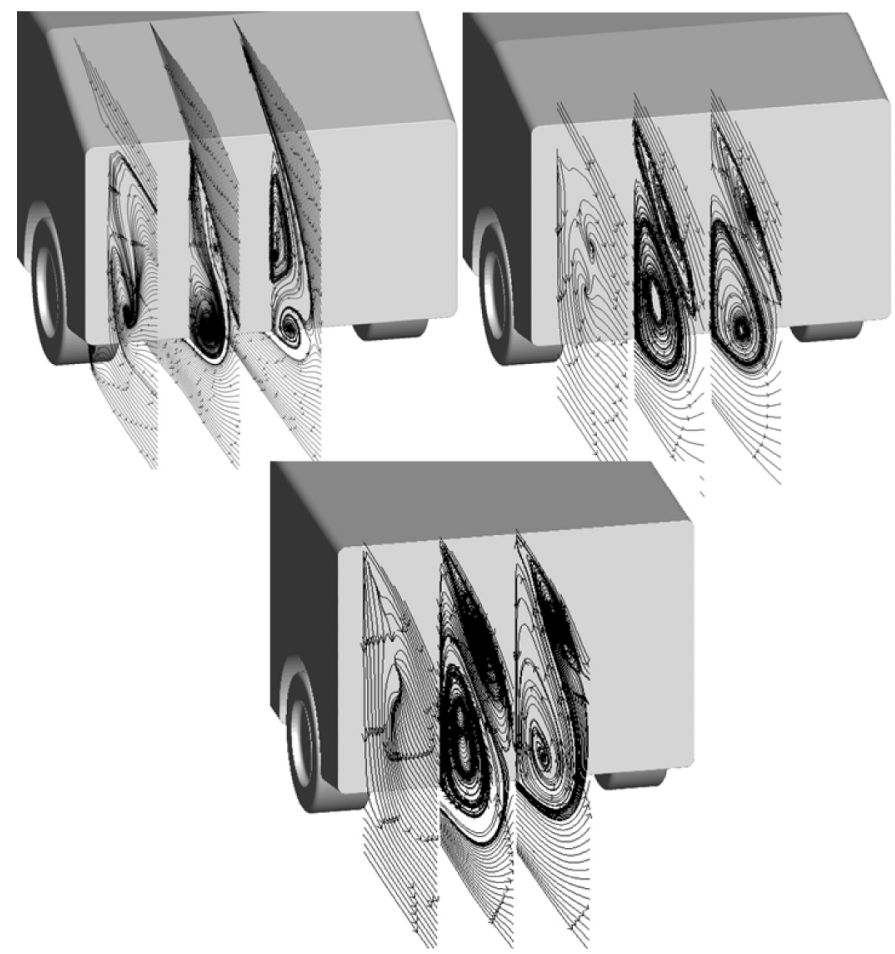

Figure 17. Projected Streamlines on XZ planes from numerical tests. Decreasing taper angle clockwise from top-left. Streamlines at $y=0,90$ and $173 \mathrm{~mm}$ (time averaged)

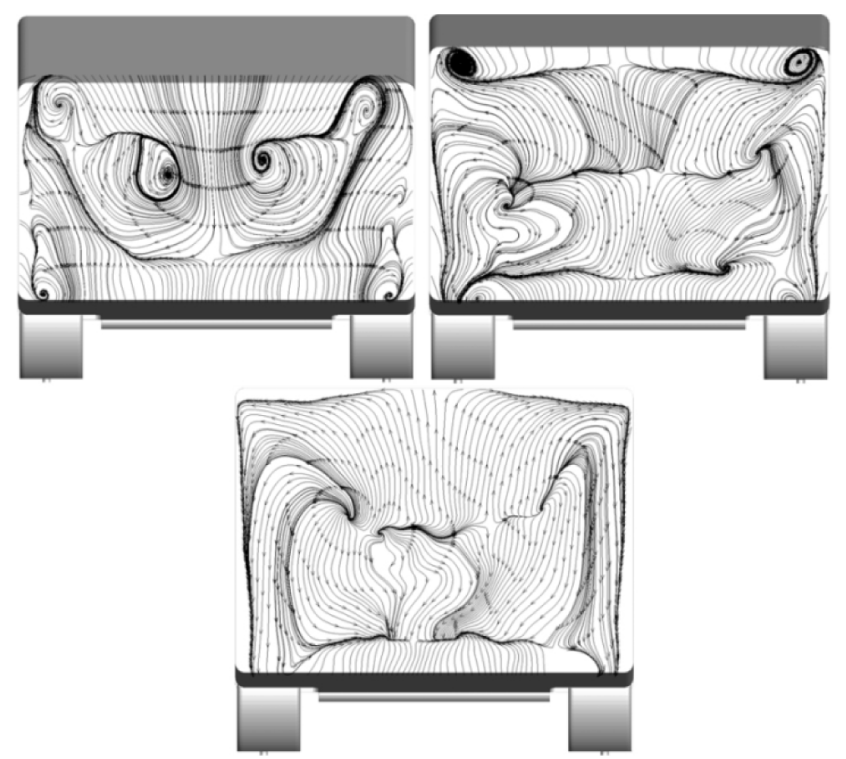

Figure 18. Projected Streamlines on $\mathrm{YZ}$ plane at $\mathrm{X}=0.1 \mathrm{~m}$ from the base; Numerical tests. Decreasing taper angle clockwise from top-left.
Figure 19 shows the inetgrated numerical contamination evolution over time. The injection begins at $0 \mathrm{~s}$, with the first contamination event occurring around $0.05 \mathrm{~s}$ later. The injection stops at $1 \mathrm{~s}$, resulting in contamination for another $0.2 \mathrm{~s}$. Figure 19 clearly suggests the presence of multiple dynamics within the soiling process. For both the 0 degree and 20 degree taper there are higher frequency events superimposed on a low frequency process. The 10 degree taper is much more linear, but with some higher frequency components still visible. This clearly shows that quantitative comparisons of soiling rates between experimental and numerical tests cannot be reasonably justified without ensuring sufficient time for one complete low frequency cycle to occur.

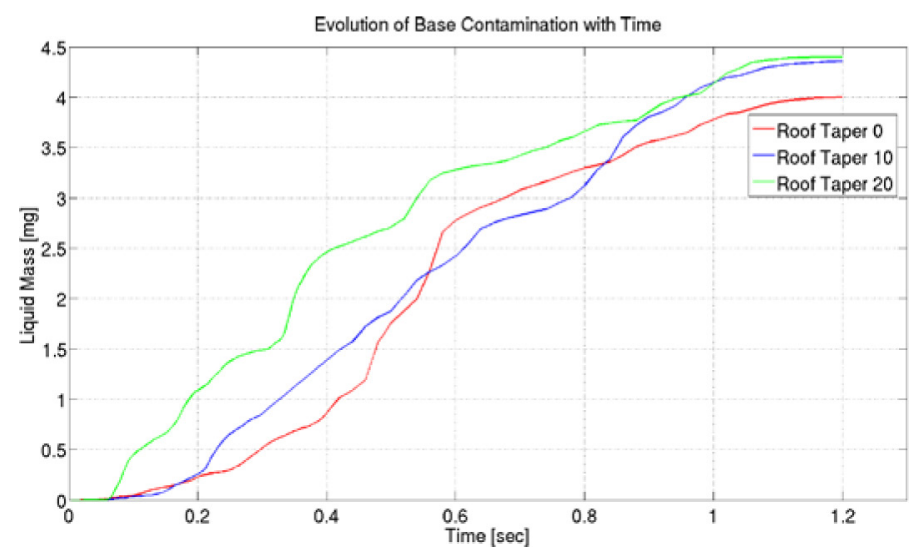

Figure 19. Numerical evolution of contamination

\section{CONCLUSIONS}

This paper presents a parametric study that looks into the effect of rear-end geometry on rear-surface contamination. Three configurations of the generic SUV model have been considered. Experiments and CFD were used to analyse the influence of roof tapers on the base contamination.

PDA measurements of a spray injector were performed to characterise the spray droplet size and velocity distributions used in the experimental soiling tests. To ensure comparability the measured characteristics were used as input to the numerical simulations.

Soiling experiments in the wind tunnel were conducted for the three SUV configurations and image processing techniques used to extract the qualitative information of the base contamination. This allowed for the comprehensive analysis of data, as well as providing validation of CFD simulations.

Computational work used the IDDES formulation of the SpalartAllmaras Detached Eddy Model together with the Lagrangian particle tracking model. Although the base pressures are predicted to be slightly larger than those obtained in experiments, the overall pressure distribution is matched well, leading to credible qualitative agreement for base contamination. It is realised that computations require running longer than $1 \mathrm{~s}$ to obtain a better averaged patterns of contamination and yield quantitative data such as contamination rates. 
The results show that as the taper angle increases then the location of the contamination is shifted outwards and down from the roof. Further, it becomes less dispersed. The numerical results suggest that there are multiple dynamics in the contamination process that have not previously been identified; every configuration possess a minimum test time required to sufficiently capture all the dynamic processes.

The CFD agrees reasonably well with experiments, with a number of possible reasons for discrepancies; this includes the accurate representation of the wake structure, particularly the rear pillar vortices for the 20 degree taper. It is possible a lack of droplet break-up, evaporation and droplet interaction models may play an important role and are important avenures for future work. The simulations predict location well enough to be used in positioning key elements such as cameras and number plate on the vehicle base.

Further work requires consideration of the low frequency dynamics in the wake to ensure that all feasible events are captured and considered. In turn, this will allow for direct comparison between experimental and numeric contamination rates.

Experimental results can be improved by increasing the fluorescence resolution; an UV lamp of greater power, or an increased dye concentration are recommended. This will provide a higher to signal-to-noise ratio but must be controlled to ensure that any asymptotic behaviour normally observed in Beer-Lambert style fits are minimised.

\section{REFERENCES}

1. Hagemeier T., Hartmann M., and Thevenin D.. Practice of vehicle soiling investigations: A review. International Journal of Multiphase flow, 37(8):860-875,doi:10.1016/j.ijmultiphaseow.2011.05.00, 2011.

2. Maycock G.. The problem of water thrown up by vehicles on wet roads. In Road Research Laboratory Report No.4, Harmondsworth, Harmondsworth, 1966.

3. Gaylard, A. and Duncan, B., "Simulation of Rear Glass and Body Side Vehicle Soiling by Road Sprays," SAE Int. J. Passeng. Cars - Mech. Syst. 4(1):184-196, 2011, doi:10.4271/2011-01-0173.

4. Watkins S.. Spray from Commercial Vehicles: A Method of Evaluation and Results from Road Tests. In Browand F., McCallen R., and Ross J., editors, The Aerodynamics of Heavy Vehicles II; Trucks, Buses, and Trains, pages 387-402, doi:10.1007/978-3-540-85070-0-36. Springer Berlin Heidelberg, 2009.

5. Manser M., Koppa R., and Mousley P.. Evaluation of Splash and Spray Suppression Devices on Large Trucks DuringWetWeather. AAA Foundation for Traffic Safety, pages 1-56, 2003.

6. Jilesen, J., Gaylard, A., Duncan, B., Konstantinov, A. et al., "Simulation of Rear and Body Side Vehicle Soiling by Road Sprays Using Transient Particle Tracking," SAE Int. J. Passeng. Cars - Mech. Syst. 6(1):424-435, 2013, doi:10.4271/2013-01-1256.

7. Gaylard, A., Pitman, J., Jilesen, J., Gagliardi, A. et al., "Insights into Rear Surface Contamination Using Simulation of Road Spray and Aerodynamics," SAE Int. J. Passeng. Cars - Mech. Syst. 7(2):673-681, 2014, doi:10.4271/2014-01-0610.

8. Gaylard, A. and Duncan, B., "Simulation of Rear Glass and Body Side Vehicle Soiling by Road Sprays," SAE Int. J. Passeng. Cars - Mech. Syst. 4(1):184-196, 2011, doi:10.4271/2011-01-0173.
9. Kabanovs, A., Varney, M., Garmory, A., Passmore, M. et al., "Experimental and Computational Study of Vehicle Surface" Contamination on a Generic Bluff Body," SAE Technical Paper 201601-1604, 2016, doi:10.4271/2016-01-1604.

10. Kuthada T. and Cyr s., 'Approaches to Vehicle Soiling', Progress in Vehicle Aerodynamics, Numerical methods. Renningen: Expert-Verlag, vol. IV, pp. 111-123, 2006.

11. Perry, A., Passmore, M., and Finney, A., "Influence of Short Rear End tapers on the Base Pressure of a Simplified Vehicle.," SAE Int. J. Passeng. Cars - Mech. Syst. 8(1):317-327, 2015, doi:10.4271/2015-01$\underline{1560 .}$.

12. Johl, G., Passmore, M.A. and R, P.M., 2004. Design methodology and performance of an indraft wind tunnel. The Aeronautical Journal, 108 (1087), pp. 465-473.

13. Littlewood, R. and Passmore, M., "The Optimization of Roof Trailing Edge Geometry of a Simple Square-Back.," SAE Technical Paper 201001-0510, 2010, doi:10.4271/2010-01-0510.

14. Cooper, K.R., "Closed-test-section Wind Tunnel Blockage Corrections for Road Vehicles. Special Publication SAE SP1176," Society of Automotive Engineers, SAE, 1996.

15. Wood, A., Passmore, M., Forbes, D., Wood, D. et al., "Base Pressure and Flow-Field Measurements on a Generic SUV Model," SAE Int. J. Passeng. Cars - Mech. Syst. 8(1):233-241, 2015, doi:10.4271/2015-01$\underline{1546 .}$.

16. Jiang C., Parker M. C., Spencer A., Wigley G., Garner C. P., and Helie J., 'Droplet Size Development in a DISI Injector Fuel Spray', International Symposium on the Application of Laser and Imaging Techniques to Fluid Mechanics, no. Ic, 2016.

17. Wigley, G., Hargrave, G.K. and Heath, J., 1999. A high power, high resolution LDA/PDA system applied to gasoline direct injection sprays. Particle \& particle systems characterization, 16(1), pp.11-19.

18. Hagemeier T., Hartmann M., Kühle M., Thévenin D., and Zähringer K., 'Experimental characterization of thin films, droplets and rivulets using LED fluorescence', Experiments in Fluids, vol. 52, no. 2, pp. 361-374, 2012.

19. Spalart P. R., W.-Jou H., Strelets M., and A. S.R., 'Comments on the Feasibility of LES for Wings, and on a Hybrid RANS/LES Approach', in Advances in DNS/LES, First AFOSR Internations Conference on DNS/ LES, 1997.

20. Spalart P. R., Deck S., Shur M. L., Squires K. D., Strelets M. K., and Travin a., 'A new version of detached-eddy simulation, resistant to ambiguous grid densities', Theoretical and Computational Fluid Dynamics, vol. 20, no. 3, pp. 181-195, 2006.

21. Shur M. L., Spalart P. R., Strelets M. K., and Travin A. K., 'A hybrid RANS-LES approach with delayed-DES and wall-modelled LES capabilities', International Journal of Heat and Fluid Flow, vol. 29, no. 6, pp. 1638-1649, 2008.

22. Migdal D. and Agosta V. D., 'A Source Flow Model for Continuum Gas-Particle Flow', Journal of Applied Mechanics, vol. 34, no. 4, p. 860, 1967.

23. Schiller L. and Naumann A., 'Uber die grundlegenden berechnungen bei der schwerkraftaufbereitung', Zeitung des vereins deutscher ingenieure., pp. 77-318, 1933.

24. Saffman P. G., 'The lift on a small sphere in a slow shear flow', Journal of Fluid Mechanics, vol. 22, no. 02, p. 385, 1965.

25. Gosman A. D. and Ioannides E., 'Aspects of Computer Simulation of Liquid-Fueled Combustors', Journal of Energy, vol. 7, no. 6, pp. 482490, doi:10.2514/3.62687, 1983.

26. Forbes D., Page G., Passmore M., and Gaylard A., 'Computational study of wake structure and base pressure on a generic SUV model.', IMechE: The International Vehicle Aerodynamics Conference, 2014.

27. Varney, M., Passmore, M., and Gaylard, A., "The Effect of Passive Base Ventilation on the Aerodynamic Drag of a Generic SUV Vehicle," SAE Int. J. Passeng. Cars - Mech. Syst. 10(1):345-357, 2017, doi:10.4271/ 2017-01-1548. 


\section{Contact Information}

Kabanovs

a.kabanovs@1boro.ac.uk

Hodgson

g.hodgson@,lboro.ac.uk

Garmory

a.garmory@lboro.ac.uk

Passmore

m.passmore@1boro.ac.uk

Gaylard

agaylar1@jaguarlandrover.co.uk

\section{ACKNOWLEDGMENTS}

This work was supported by Jaguar Land Rover and the UK Engineering and Physical Sciences Research Council grant EP/ K014102/1 as part of the jointly funded Programme for Simulation Innovation. Calculations were performed on HPC-Midlands funded by the UK EPSRC, Grant ref EP/K000063/1. Further thanks to Mr. Dave Cooper for his work manufacturing the different model geometries for testing and to Dr. Changzhao Jiang for his assistance in obtaining the PDA results.

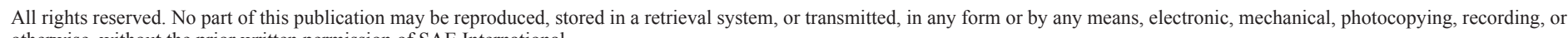
otherwise, without the prior written permission of SAE International.

Positions and opinions advanced in this paper are those of the author(s) and not necessarily those of SAE International. The author is solely responsible for the content of the paper. 